\title{
Epithelial Cell Adhesion Molecule mRNA Can be a Potential Marker to Predict Metastasis in Hepatocellular Carcinoma Patients
}

\author{
Iman A Abdelgawad*
}

\begin{abstract}
Objectives: Epithelial cell adhesion molecule [EpCAM] is a surface marker of cancer stem cells that can maintain the capacity for malignant proliferation, invasion, metastasis, and tumor recurrence; hence its detection among hepatocellular carcinoma [HCC] patients may be an important prognostic factor. The aim of this study was to detect EpCAM mRNA expression in the whole blood of HCC patients and normal control subjects to elucidate its clinico-pathological significance among patients with HCC. Methods: This study was conducted on 74 newly diagnosed HCC patients and forty normal control subjects. Both groups were subjected to the detection of EpCAM mRNA in the whole blood using reverse transcriptase polymerase chain reaction [RT- PCR] technique. EpCAM expression was compared with some of the established prognostic factors of HCC. Results: EpCAM was detected in 17.5\% of the HCC cases and was not expressed in any of the normal control subjects. EpCAM positive cases showed higher serum levels of alpha- feto protein [AFP] and carcinoembryonic antigen [CEA]. Prevalence of EpCAM positivity gave significant results with distant metastasis, lymph node metastasis, and portal vein thrombosis. Conclusion: EpCAM proved high specificity among HCC patients and its expression was associated with metastasis and portal vein thrombosis. Higher serum levels of CEA among the EpCAM positive patients may attract the attention to a subgroup of HCC patients who are more liable to develop metastasis.
\end{abstract}

Keywords: EpCAM- HCC- metastasis- RT-PCR

Asian Pac J Cancer Prev, 21 (3), 861-866

\section{Introduction}

Liver cancer is predicted to be the sixth most commonly diagnosed cancer and the fourth leading cause of cancer death worldwide in 2018. In total, there were 841,080 cases of liver cancer worldwide in 2018 (4.7\% of all cancer sites) with 781,631 deaths $(8.2 \%$ of all cancer deaths) (GLOBOCAN, 2018).

TROP1 and tumor-associated calcium signal transducer 1 are other names for epithelial cell adhesion molecule which is a $30-40 \mathrm{kDa}$ type I membrane protein of 314 amino acids. Mutations in the EPCAM gene have been linked to Hereditary Non-Polyposis Colorectal Cancer, which is a well-known cancer susceptibility syndrome that predisposes to many types of cancer, particularly, colorectal adenocarcinoma and endometrial carcinoma, (Pathak et al., 2019). It is widely expressed on the surface of epithelial cells and epithelial-derived tumor cells, and is important for cell adhesion, proliferation, differentiation, signal transduction, and tissue regeneration (Huang et al., 2018). It is also considered an important marker for hepatic progenitor cells (HPCs), which are thought to have a crucial role in the production new hepatocytes, cell fate decisions, cell migration and differentiation (Atsunori et al., 2019). Only about $35 \%$ of HCC cases express EpCAM, although HCC cells are epithelial in origin (Yamashita et al., 2008).

EpCAM has recently been recognized as a surface marker of cancer stem cells (CSCs) (Fouse et al., 2013). EpCAM-positive HCC cells display some of the liver cancer stem cell-like characters which include; self-renewal and differentiation, maintaining the capacity for malignant proliferation, invasion, metastasis, and tumor recurrence (Campbell et al., 2007). These findings indicate that EpCAM may serve in the targeted therapy against cancer which might offer a promising and a novel approach for the treatment of the poor prognosis types of HCC (Ogawa et al., 2014).

Analyzing the circulating tumor cells (CTCs) characteristics in the peripheral blood of cancer patients is both rapid and convenient, which might help in the diagnosis, prognosis prediction, and evaluation of the response to treatment (Slade et al., 2009).

Occult tumor cells may remain dormant for up to 22 years in the circulation. Later, these cells might cause tumor relapse and metastasis (Meng et al., 2004). Such 
cells may express different biological characteristics from the primary tumor and may play an important role in tumor recurrence (Stakenborg et al., 2010). CTCs frequently shed into the blood of cancer patients, but in the circulation, most of them usually undergo apoptosis being affected by the immune cells and changes in the microenvironment, or destructed by the shearing forces in the blood vessels. So, only a very small proportion of CTCs can survive, and when given optimum conditions, they may spread and form micro metastases (Mocellin et al., 2006).

HCC recurrence commonly occurs via hematogenous spread (Imamura et al., 2003); which highlights the significance of CTCs detection in predicting HCC recurrence and monitoring of therapy. The greatest challenge of this field is to discriminate the tumor-derived cells from the healthy cells and their content. As most cancers are epithelial in origin, targeting EpCAM therefore became the most commonly used epithelial marker for the capture of CTCs in the blood circulation of carcinoma patients (Antonarakis et al., 2017; Carter et al., 2017).

The aim of this study was to detect the EpCAM mRNA expression in the whole blood of HCC patients and normal control subjects and to elucidate its clinico-pathological significance among patients with HCC.

\section{Materials and Methods}

This study was conducted on 74 newly diagnosed HCC patients who presented to the outpatient clinic at the National Cancer Institute (NCI), Cairo University over a period of 6 consecutive months from January to June 2014. The sample size was determined by the statistician. All patients who were eligible to the study and were proven to have HCC by their clinical presentation, computed tomography (CT), magnetic resonance imaging (MRI) or by liver biopsy were included. Cirrhosis and PVT are diagnosed by ultrasound or MRI. There were 52 males and 22 females, and their age ranged from 40 to 81 years. Forty apparently healthy volunteers were included as a normal control group. There were 26 males and 14 females, and their age ranged from 37 to 76 years.

All procedures followed were in accordance with the ethical standards of the responsible committee on human experimentation (institutional and national) and with the Helsinki Declaration of 1975, as revised in 2008 (Yamashita et al., 2008).

\section{Inclusion criteria}

All patients with either sex who were confirmed to have HCC were included in the study prior to any therapeutic intervention.

\section{Exclusion criteria}

Patients with other concomitant malignancies or received any line of cancer therapy were excluded.

Blood samples from all patients and control subjects were subjected to the following

1- Liver function tests using Beckman CX9 auto-analyzer.

2- Tumor Markers: AFP and CEA were done using
Axsym based on the micro-particle enzyme immunoassay (MEIA) technology.

3- Detection of EpCAM mRNA expression in the whole blood by RT-PCR

Seven milliliters of whole blood were collected on EDTA containing vacutainers for all patients and control subjects. Isolation of mononuclear cells was performed using Ficoll-Hypaque (Bøyum, 1968). RNA extraction was done from mononuclear cells using InviTrap Spin Blood RNA Mini Kit according to manufacturer's instructions. The concentration and purity of RNA was determined by measuring its absorbance at $260 \mathrm{~nm}$ and $280 \mathrm{~nm}$ using nanodrop. Concentrations ranged from $(40-80 \mathrm{ng} / \mu \mathrm{l})$ and purity $(1.9-2.1)$. One $\mu \mathrm{g}$ RNA was reversely transcribed using high capacity cDNA reverse transcription kit (Applied Biosystems). Reverse transcription was performed in $20 \mu \mathrm{l}$ reaction containing $1 \mathrm{x}$ RT buffer, $0.2 \mathrm{mM}$ DNTP, 1x RT random primer, 50U multiscribe TM reverse transcriptase and nuclease free water. The reaction was performed at $25^{\circ} \mathrm{C}$ for $10 \mathrm{~min}$, followed by $37^{\circ} \mathrm{C}$ for $120 \mathrm{~min}$ and $85^{\circ} \mathrm{C}$ for $5 \mathrm{~min}$ then kept at $4^{\circ} \mathrm{C}$. The reaction for $\beta$ actin was performed in $25 \mu$ reaction containing $1 \mu \mathrm{l}$ cDNA, $1 \mathrm{x}$ master mix, 25 pmole of each primer F: 5'-GTGGGGCGCCCCAGGCACCA-3' and R: 5' -CTCCTTAATGTCACGCACGATTTC-3' (Inoue et al., 1994). The cyclic condition consisted of initial denaturation at $94^{\circ} \mathrm{C}$ for $5 \mathrm{~min}$, followed by 30 cycles of denaturation at $94^{\circ} \mathrm{C}$ for $1 \mathrm{~min}$, annealing at $63^{\circ} \mathrm{C}$ for $2 \mathrm{~min}$ and extension at $72^{\circ} \mathrm{C}$ for $3 \mathrm{~min}$. Four $\mu$ l of cDNA was used as template for EpCAM amplification performed in $25 \mu \mathrm{l}$ reaction containing $1 \mathrm{x}$ buffer, 25 pmole of each primer F: 5'- GGACCTGACAGTAAATGGGGAAC -3' and R: 5' - CTCTTCTTTCTGGAAATAACCAGCAC -3' (Yamashita et al., 2008)., 2U Hot Firepol DNA polymerase [Solis Biodyne], $1 \mathrm{X}$ buffer, $1.5 \mathrm{mM} \mathrm{MgCl}_{2}$ and $200 \mu \mathrm{M}$ of each deoxynucleotide triphosphate. The cyclic condition consisted of initial denaturation at $95^{\circ} \mathrm{C}$ for $15 \mathrm{~min}$, followed by 45 cycles of denaturation at $94^{\circ} \mathrm{C}$ for $1 \mathrm{~min}$, annealing at $66^{\circ} \mathrm{C}$ for $1 \mathrm{~min}$, extension at $72^{\circ} \mathrm{C}$ for $1 \mathrm{~min}$ and final elongation at $72^{\circ} \mathrm{C}$ for $7 \mathrm{~min}$. The PCR products were visualized on $2 \%$ agarose and were $540 \mathrm{bp}$ for $\beta$ actin and 186 bp for EpCAM.

\section{Statistical analysis}

Data analysis was done by using IBM SPSS advanced statistics version 20 (SPSS Inc., Chicago, IL). The descriptive measures were presented in frequency and percentages. For quantitative data, comparison between two groups was done using Mann-Whitney (non-parametric t-test). Chi square test was used to test prevalence of proportions. P-value of $\leq 0.05$ was considered significant.

\section{Results}

Patients' characteristics are mentioned in Table 1. EpCAM was detected in 13/74 (17.5\%) of the HCC cases, while all normal control subjects were negative for EpCAM expression. Distant and lymph node metastases were detected in (19\% and $27 \%)$ of patients respectively. Thirty $\%$ of patients were cirrhotic, $13.5 \%$ had portal vein 
Table 1. Patients' Characteristics

\begin{tabular}{|c|c|c|c|}
\hline Characteristic & & $\mathrm{N}(74)$ & Percentage \\
\hline $\begin{array}{l}\text { Age (median and } \\
\text { interquartile range) }\end{array}$ & $61(55-67)$ & & \\
\hline \multirow[t]{2}{*}{ Sex } & Males & 51 & 69 \\
\hline & Females & 23 & 31 \\
\hline \multirow[t]{2}{*}{ EpCAM } & Positive & 13 & 17.5 \\
\hline & Negative & 61 & 82.5 \\
\hline \multirow[t]{4}{*}{ Stage } & I & 13 & 18 \\
\hline & II & 35 & 47 \\
\hline & III & 18 & 24 \\
\hline & IV & 8 & 11 \\
\hline \multirow[t]{2}{*}{ Distant metastasis } & Present & 14 & 19 \\
\hline & Absent & 60 & 81 \\
\hline \multirow[t]{2}{*}{ Lymph nodes involvement } & Present & 20 & 27 \\
\hline & Absent & 54 & 73 \\
\hline \multirow[t]{2}{*}{ Cirrhosis } & Present & 22 & 30 \\
\hline & Absent & 52 & 70 \\
\hline \multirow[t]{2}{*}{ Portal vein thrombosis } & Present & 10 & 13.5 \\
\hline & Absent & 64 & 86.5 \\
\hline \multirow[t]{2}{*}{ Hepatitis virus infection } & Positive & 19 & 26 \\
\hline & Negative & 55 & 74 \\
\hline
\end{tabular}

EpCAM, Epithelial cell adhesion molecule thrombosis, 35\% had advanced disease stage (III and IV), while $26 \%$ suffered from hepatitis viral infection.

In Table 2, both AFP and CEA showed significantly higher levels among the EpCAM positive cases compared to the EpCAM negative cases $(\mathrm{P}=0.022$ and 0.024$)$ respectively, while Table 3 shows the comparison of some prognostic factors of HCC according to the positivity of EpCAM expression, which showed significant results with distant metastasis, lymph node metastasis and portal vein thrombosis (PVT).

On comparing cases with CEA levels $>5 \mathrm{ng} / \mathrm{ml}$ and cases with AFP levels $>400 \mathrm{ng} / \mathrm{ml}$ according to the positivity of EpCAM expression, patients with positive EpCAM expression showed significantly higher levels of CEA $(>5 \mathrm{ng} / \mathrm{ml})(\mathrm{P}=0.048)$, while no significant results were detected regarding AFP.

\section{Discussion}

Recent studies have revealed that EpCAM is over-expressed in a variety of human cancers, including HCC (Yamashita et al., 2008).

Although HCC cells are epithelial in origin, only about $35 \%$ of HCC cases express EpCAM (Yamashita et al., 2008). This comes in line with our findings as only $17.5 \%$ of patients with HCC were positive for EpCAM

Table 2. Comparison of AFP, CEA and Liver Enzymes According to the Positivity of EpCAM

\begin{tabular}{cccccccc}
\hline & & Age (years) & $\begin{array}{c}\text { AFP } \\
(<10 \mathrm{ng} / \mathrm{ml})\end{array}$ & $\begin{array}{c}\text { CEA } \\
(0-3 \mathrm{ng} / \mathrm{mL})\end{array}$ & $\begin{array}{c}\text { AST } \\
(10-40 \text { units } / \mathrm{L})\end{array}$ & $\begin{array}{c}\text { ALT } \\
(7-56 \text { units } / \mathrm{L})\end{array}$ & $\begin{array}{c}\text { ALP } \\
44 \text { to } 147 \mathrm{IU} / \mathrm{L})\end{array}$ \\
\hline \multirow{2}{*}{ EpCAM } & Neg (61) & $60(54-67)$ & $56(17-189)$ & $5(3-6.4)$ & $56(33-74)$ & $38(26-56)$ & $132(109-163)$ \\
& Pos (13) & $65(60-68)$ & $358(40-673)$ & $6.6(5-30.5)$ & $59(36-67)$ & $45(39-54)$ & $152(146-166)$ \\
& p-value & 0.243 & $0.022^{*}$ & $0.024^{*}$ & 0.949 & 0.486 & 0.102 \\
\hline
\end{tabular}

*, Significant; Median and interquartile range in parenthesis; EpCAM, Epithelial cell adhesion molecule; AFP, Alpha-feto protein; CEA, Carcinoembryonic antigen; AST, Aspartate aminotransferase; ALT, Alanine aminotransferase; ALP, Alkaline phosphatase.

Table 3. Comparison of Some Prognostic Factors of HCC According to the Positivity of EPCAM

\begin{tabular}{|c|c|c|c|c|c|}
\hline & & EpCAM neg (n 61) & EpCAM pos (n 13) & Chi square & $\mathrm{P}$ value \\
\hline \multirow[t]{2}{*}{ Sex } & Males & 40 & 11 & & \\
\hline & Females & 21 & 2 & 1.1 & 0.31 \\
\hline Distant & Present & 7 & 7 & & \\
\hline metastasis & Absent & 54 & 6 & 9.9 & $0.002 *$ \\
\hline Lymph node & Present & 9 & 11 & & \\
\hline metastasis & Absent & 52 & 2 & 23.1 & $<0.001^{*}$ \\
\hline \multirow[t]{2}{*}{ PVT } & Present & 2 & 8 & & \\
\hline & Absent & 59 & 5 & 26.3 & $<0.001^{*}$ \\
\hline \multirow[t]{2}{*}{ Cirrhosis } & Present & 15 & 7 & & \\
\hline & Absent & 46 & 6 & 3.1 & 0.078 \\
\hline \multirow[t]{2}{*}{ Hepatitis } & Present & 16 & 3 & & \\
\hline & Absent & 45 & 10 & 0.01 & 0.92 \\
\hline \multirow[t]{5}{*}{ Stage } & I & 11 & 2 & & \\
\hline & II & 27 & 8 & & \\
\hline & III & 15 & 3 & & \\
\hline & IV & 8 & 0 & 0 & 1 \\
\hline & IV & 8 & 0 & 0 & 1 \\
\hline
\end{tabular}

*, Significant; EpCAM, Epithelial cell adhesion molecule; PVT, Portal vein thrombosis. 
expression. On the other hand, all normal control subjects were negative for EpCAM expression, which reflects its high specificity among the cancer patients. Similarly, no healthy or benign liver disease subjects had CTCs detected in a study by Wen Xu et al., (2011). Although CTCs are either not detected or are extremely rare in healthy individuals or patients with benign conditions, there is no sufficient data to describe the incidence of circulating EpCAM-positive epithelial cells commonly associating HCC, as liver injury, cirrhosis, or viral hepatitis (Schulze et al., 2013).

Being easily accessible, CTCs might be considered as promising candidates to predict tumor aggressiveness, recurrence and metastasis (Sun et al., 2013). However, their rarity in the peripheral blood of the patients might limit their clinical utility. It has been proven that EpCAM-positive CTCs may serve as a prognostic marker in HCC after curative resection, as overexpression of EpCAM is significantly associated with the poor clinical outcome of HCC (Sun et al., 2013).

In this study, among the EpCAM positive subjects, 7/13 (54\%) had distant metastasis, 11/13 (85\%) had LN metastasis, and 8/13 (61.5\%) had PVT. The prevalence of positivity of EpCAM expression gave significant results when compared to these 3 prognostic factors, but not with the disease stage or other tested prognostic factors which is contradictory to the results detected by other investigators who found that EpCAM-positive cancer patients commonly exhibit an advanced tumor stage (Sun et al., 2013; Anthony et al., 2014).

Serum alpha-feto protein (AFP) is commonly used for diagnosis and surveillance of HCC and has been suggested as an independent indicator for prognosis as HCC patients with a high serum AFP levels tend to have shorter survival (Llovet et al., 2012). However, it lacks sufficient sensitivity and specificity, as about $30 \%$ to $40 \%$ of HCC patients are AFP negative, and AFP mRNA was reported to be detected in patients with cirrhosis or chronic hepatitis B infection (Aselmann et al., 2001). RT-PCR for AFP or albumin has been used to detect CTCs among HCC patients (Ijichi et al., 2002); however, results are inconsistent due to their low specificity.

It has been detected that EpCAM-positive CTCs are associated with bad prognostic criteria; as high AFP, presence of vascular invasion, and poor differentiation (Yamashita et al., 2013). These findings support the potential role of CTCs in prognostic stratification of patients and treatment decision-making among patients with HCC, which has been challenged before by the great prognostic heterogeneity of this disease (Kelley et al., 2013).

Supporting these findings, we detected higher serum levels of AFP among the EpCAM positive cases compared to the EpCAM negative cases $(\mathrm{P}=0.022)$. Five out of 13 (38\%) of the EpCAM positive cases, had AFP levels $>400$ $\mathrm{ng} / \mathrm{dl}$.

Carcinoembryonic antigen (CEA) is an immunoglobulin superfamily cell surface glycoprotein that might play a role as an adhesion molecule (Jessup et al., 1989). Since alterations in cell adhesion are believed to be involved in cancer invasion and metastasis, it was further suggested that CEA may play a role in these processes (Jessup et al., 1989).

EpCAM has been reported to promote tumor formation and metastasis either by disrupting the link between a-catenin and F-actin (Winter et al., 2003) or by facilitating the immune escape of tumor cells (Winter et al., 2003). This supports the significant results between prevalence of EpCAM expression and the presence of both distant metastasis and lymph node metastasis in our study. Similarly, CEA is thought to play a role in the metastatic processes (Jessup et al., 1989). This can explain our findings that EpCAM positive cases showed higher serum levels of CEA compared to EpCAM negative cases $(\mathrm{P}=0.024)$. It has also been detected that 10/13 (77\%) of the EpCAM positive cases had CEA serum levels higher than $5 \mathrm{ng} / \mathrm{ml}$. Six out of these 10 patients $(60 \%)$ had concomitant distant metastasis. This can take us to the assumption that the elevation of both EpCAM and CEA in HCC patients may give a strong indicator for the presence of metastasis.

The prevalence of EpCAM expression positivity also gave significant results with portal vein tumor thrombosis (PVT), and $80 \%$ of the patients having PVT were found to be EpCAM positive, from whom $50 \%$ had CEA levels $>5 \mathrm{ng} / \mathrm{ml}$.

Supporting our results, Xu et al., (2011), detected higher positivity rate and number of detected CTCs in HCC patients with PVT compared to those patients without PVT, which suggests that PVT may also be a source of systemic spread of CTCs contradicting the previous assumption that PVT would mainly cause intrahepatic rather than distant metastases (Mitsunobu et al., 1969).

EpCAM is absent in blood cells, not expressed on mature hepatocytes and is expressed in only approximately $35 \%$ to $60 \%$ of HCC tumors by immunohistochemistry or PCR-based techniques (Kelley et al., 2013).

It is possible that non-EpCAM-expressing HCC cells exist in circulation and are undetectable by the current technologies, which may account for our inability to detect CTCs in some of our HCC patients. Adding to this, during epithelial mesenchymal transition EMT, down regulation of EpCAM is required for the invasion by cancer cells. EMT is a process via which epithelial cells gain mesenchymal characteristics that enhance their migratory capacity and invasiveness, and increase their resistance to apoptosis (Kalluri et al., 2003).

In addition, the upregulation of EpCAM expression due to regenerative activity during inflammatory reactions (Kalluri et al., 2003) which raises the possibility that upregulation of EpCAM expression in $\mathrm{HCC}$ may be partially due to the inflammatory response accompanying the underlying cause of HCC as liver cirrhosis. Collectively, all these data suggest that CTC isolation and detection in $\mathrm{HCC}$ may require combining EpCAM with other markers like CD90, and CD133 which have been used to identify potential hepatic CSCs (Ma et al., 2007). In this study we didn't examine for the presence of theses 2 markers, which we recommend for further studies.

This study has some limitations; confirmation of 
EpCAM positivity by immunocytochemistry was needed to give more precise information, also follow up of EpCAM positive cases for long durations was needed to detect the impact of EpCAM on the patients' survival and tumor metastasis. Further studies will be done to fulfill all the limitations encountered in this study.

In conclusion, EpCAM mRNA was detected in the whole blood of $17.5 \%$ of the HCC patients, while none of the normal control subjects were positive for EpCAM expression. This reflects the high specificity of EpCAM among cancer subjects. Detection of CTCs in the whole blood of HCC patients is a non-invasive procedure that can give a clue about the prognosis and treatment strategies for the HCC patients.

Higher serum levels of CEA among the EpCAM positive patients may attract the attention to a subgroup of HCC patients who carry poor prognosis and are more liable to develop metastasis and recurrence. Such group of patients may be the target for further studies to benefit from certain targeted therapies.

Further studies with larger sample sizes are recommended to evaluate the efficacy of EpCAM as a diagnostic and prognostic marker for HCC.

Quantitation of the CTCs may give more accurate results especially if meant to be used to evaluate the efficacy of treatment. Since tumor malignancy is associated with complex signaling pathways; it is desirable that CTCs be used in combination with another index, to monitor their clinical relevance.

\section{Acknowledgments}

This study was not funded. The study protocol was approved by the Scientific Research Committee and Institutional Review Board at the National Cancer Institute, Cairo University, Egypt. All procedures followed were in accordance with the ethical standards of the responsible committee on human experimentation (institutional and national) and with the Helsinki Declaration of 1975, as revised in 2008 (Yamashita et al., 2008).

This study is not a part of an approved thesis and there is no conflict of interest. A written informed consent was obtained from all patients according to the international ethics committee guidelines.

\section{Abbreviations}

HCC: Hepatocellular carcinoma

EpCAM: Epithelial cell adhesion molecule

CSCs: Cancer stem cells

CTCs: Circulating tumor cells

CT: Computed tomography

MRI: Magnetic resonance imaging

MEIA: Microparticle enzyme immunoassay

AFP: Alpha-feto protein

CEA: Carcinoembryonic antigen

PVT: Portal vein thrombosis

\section{References}

Anthony W, Joanna H, Stephen L, et al (2014). Expression of stemness markers (CD133 and EpCAM) in prognostication of hepatocellular carcinoma. Histopathology, 64, 935-50.

Antonarakis ES, Lu C, Luber B, et al (2017). Clinical significance of Androgen receptor splice variant-7 mRNA detection in circulating tumor cells of men with metastatic castration-resistant prostate cancer treated with first- and second-line abiraterone and enzalutamide. $\mathrm{J}$ Clin Oncol, 35, 2149-56.

Aselmann H, Wolfes H, Rohde F, et al (2001). Quantification of alpha 1-fetoprotein mRNA in peripheral blood and bone marrow: a tool for perioperative evaluation of patients with hepatocellular carcinoma. Langenbecks Arch Surg, 386, 118-23.

Atsunori T, Takeshi S, Chiyumi O, et al (2019). EpCAM- and/ or NCAM- Expressing hepatocellular carcinoma in which behavior of hepatic progenitor cell marker- positive cells are followed. Case Rep Gastroenterol, 13, 118-24.

Bøyum A (1968). Isolation of mononuclear cells and granulocytes from human blood. Scand J Clin. Lab Invest, 21, 77-89.

Campbell LL, Polyak K (2007). Breast tumor heterogeneity: cancer stem cells or clonal evolution?. Cell Cycle, 6, 2332-8.

Carter L, Rothwell DG, Mesquita B, et al (2017). Molecular analysis of circulating tumor cells identifies distinct copy-number profiles in patients with chemosensitive and chemorefractory small-cell lung cancer. Nat Med, 23, 114-9.

Fouse SD, Costello JF (2013). Cancer stem cells activate STAT3 the EZ way. Cancer Cell, 23, 711-3.

GLOBOCAN database (2018). Estimated cancer incidence, mortality and prevalence worldwide.

Huang L, Yang Y, Yang F, et al (2018). Functions of EpCAM in physiological processes and diseases. Int J Mol Med, 42, 1771-85.

Imamura H, Matsuyama Y, Tanaka E, et al (2003). Risk factors contributing to early and late phase intrahepatic recurrence of hepatocellular carcinoma after hepatectomy. J Hepatol, 38, 200-7.

Inoue K, Sugiyama H, Ogawa H, et al (1994). Expression of the interleukin-6 (IL-6), IL-6 receptor, and gp130 genes in acute leukemia. Blood, 84, 2672-80.

Ijichi M, Takayama T, Matsumura M, et al (2002). Alpha-Fetoprotein mRNA in the circulation as a predictor of postsurgical recurrence of hepatocellular carcinoma: a prospective study. Hepatology, 35, 853-60.

Jessup JM, Thomas P (1989). Carcinoembryonic antigen: function in metastasis by human colorectal carcinoma. Cancer Metastasis Rev, 8, 263-80.

Kalluri R, Neilson EG (2003). Epithelial-mesenchymal transition and its implications for fibrosis. J Clin Invest, 112, 1776-84.

Kelley RK, Venook AP (2013). Novel therapeutics in hepatocellular carcinoma: how can we make progress?. Am Soc Clin Oncol Educ Book, doi: 10.1200/EdBook AM.2013.33.e137.

Llovet JM, Pena CE, Lathia CD, et al (2012): Plasma biomarkers as predictors of outcome in patients with advanced hepatocellular carcinoma. Clin Cancer Res, 18, 2290-300.

Ma S, Chan KW, Hu L, et al (2007). Identification and characterization of tumorigenic liver cancer stem/progenitor cells. Gastroenterology, 132, 2542-56.

Meng S, Tripathy D, Frenkel EP, et al (2004). Circulating tumor cells in patients with breast cancer dormancy. Clin Cancer Res, 10, 8152-62.

Mitsunobu M, Toyosaka A, Oriyama T, et al (1996). Intrahepatic metastases in hepatocellular carcinoma: the role of the portal vein as an efferent vessel. Clin Exp Metastasis, 14, 520-9.

Mocellin S, Keilholz U, Rossi CR, et al (2006). Circulating tumor cells: the 'leukemic phase' of solid cancers. Trends Mol Med, 12,130-9.

Ogawa K, Tanaka S, Matsumura S, et al (2014). EpCAM-targeted 
therapy for human hepatocellular carcinoma. Ann Surg Oncol, 21, 1314-22.

Pathak SJ, Mueller JL, Okamoto K, et al (2019). EPCAM mutation update: Variants associated with congenital tufting enteropathy and Lynch syndrome. Hum Mutat, 40, 142-61.

Schulze K, Gasch C, Staufer K, et al (2013). Presence of EpCAM-positive circulating tumor cells as biomarker for systemic disease strongly correlates to survival in patients with hepatocellular carcinoma. Int J Cancer, 133, 2165-71.

Slade MJ, Payne R, Riethdorf S, et al (2009). Comparison of bone marrow, disseminated tumour cells and blood-circulating tumour cells in breast cancer patients after primary treatment. Br J Cancer, 100, 160-6.

Stakenborg T, Liu C, Henry O, et al (2010). Automated genotyping of circulating tumor cells. Expert Rev Mol Diagn, 10, 723-9.

Sun YF, Xu Y, Yang XR, et al (2013). Circulating stem cell-like EpCAM + tumor cells indicate poor prognosis of hepatocellular carcinoma after curative resection. Hepatology, 57, 1458-68.

Winter MJ, Nagelkerken B, Mertens AE, et al (2003). Expression of EpCAM shifts the state of cadherin-mediated adhesions from strong to weak. Exp Cell Res, 285, 50-8.

$\mathrm{Xu} \mathrm{W}$, Cao L, Chen L, et al (2011). Isolation of circulating tumor cells in patients with hepatocellular carcinoma using a novel cell separation strategy. Clin Cancer Res, 17, 3783-93.

Yamashita T, Forgues M, Wang W, et al (2008). EpCAM and alpha-fetoprotein expression defines novel prognostic subtypes of hepatocellular carcinoma. Cancer Res, $\mathbf{6 8}$, 1451-61.

Yamashita T, Honda M, Nakamoto Y, et al (2013). Discrete nature of $\operatorname{EpCAM}(+)$ and $\mathrm{CD} 90(+)$ cancer stem cells in human hepatocellular carcinoma. Hepatology, 57, 1484-97.

\section{๑๐。}

This work is licensed under a Creative Commons AttributionNon Commercial 4.0 International License. 